Journal of Social Sciences 7 (2): 257-264, 2011

ISSN 1549-3652

(C) 2010 Science Publications

\title{
The Perceived Leader Support Behavior for Subordinate's Creativity: The Moderating Effect of Trust
}

\author{
${ }^{1}$ Kuo-Hsiung Chen, ${ }^{2}$ Jui-Mei Yien and ${ }^{3}$ Chien-Jung Huang \\ ${ }^{1}$ Department of Business Administration, Cheng Shiu University, Taiwan \\ ${ }^{2}$ Department of Leisure Management, University of Kang Ning, Taiwan \\ ${ }^{3}$ Department of Marketing and Distribution Management, \\ Fortune Institute of Technology, Taiwan
}

\begin{abstract}
Problem statement: The main goal behind this study tries to figure out whether or not the leader's supportive behavior will influence subordinates' creativity and is there any affection of trust between leaders' supportive behavior and subordinates' creativity? Approach: This study was conducted to examine the relationships between leader support behavior and subordinate creativity and the moderating effect of trust on subordinates' creativity under the leader support behavior. Results: From the analysis, we found the supportive behavior of leaders, employees' creativity and employee to leaders' trust is significant related and trust is also partial moderating. Conclusion: Based on the finding of the this study, we argue that leadership of creative subordinates required leader support behavior and trust in management, thus, the creativity in organization could be enhanced.
\end{abstract}

Key words: Leader's supportive behavior, influence subordinates, subordinates' creativity, affection of trust, employee's creativity, dyadic trust, exploit creativity, banish self-seeking, multidimension perspective

\section{INTRODUCTION}

The importance of innovation to 20th century is as systematic view to 50 ages, TQM to 80 ages, time and efficiency management to 90 ages, which are the key factors for maintaining the competition of an organization (Jaussi and Dionne, 2003). It is necessary for a company to get the competition advantage by concentrating on the production to creativity (Drucker, 2000). Not just improve the process, quality, technology, or provide new service and product but also handle the competitor from national to international (Andriopoulos and Lowe, 2000; Cummings and Oldham, 1997). Innovation is the only way to survive and run for the organization in the long-term and multichanging environment (Dess and Pickens, 2000; Tushman and O' Reilly, 1997).

The performance of an enterprise comes from its employees' creativity. Amabile (1988) pointed out creativity is the knowledge base of innovation. In fact, personal creativity is influenced by specific personal characteristic and environment factors. Many researches said creativity is not equal intelligence; such as Sterberg and Lubart (1995). Researchers found that environment factors have more to do with the creativity (Amabile, 1988; Woodman et al., 1993). The only way is staying in the creativity surrounding to simulate new ideas for better organizational innovation. So, creativity can be created and how to simulate employees' creativity will be an important task.

There are many organizational environment factors to influence employees' cognition. Sternberg and Lubart (1995) all believed that the member of organization was influenced by many organization's powers, such as leadership, group cohesiveness and so on. Those surrounding factors all prevent employees' creativity and most of them were controlled by leader's dominance. Leaders effect employee's creativity most (Hage and Dewar, 1973), especially in the supportive degree of innovation, if leaders guide them with high support and low control (Oldham and Cummings, 1996) or with democracy and caring leadership (Kanter, 1983), that would help employees to have creativity. From literatures we found the research of leader and creativity concentrated more on how leaders "support" the idea of innovation, so what kind of behavior will cause employees to feel supported is going to be concerned.

Corresponding Author: Chien-Jung Huang, Department of Marketing and Distribution Management, Fortune Institute of Technology, Taiwan 


\section{J. Social Sci., 7 (2): 257-264, 2011}

At the same time of exploiting the creativity, the employee will let himself or herself get into a dangerous situation because the new idea sometimes involves risk, uncertain and fail (Andriopoulos and Lowe, 2000; Rubenson and Runco, 1992). However, not only for employees but leaders have the same degree of failing risk under this situation, so trust between each other is really important (Smith, 2002). The leader has to trust the ability of employees and employees have to trust the promise of innovation of the leader. Also the research of team climate for innovation believed building a circumstance for developing creativity will be important to include trust and the feeling of safeness (Chandler et al., 2000; Ragazzoni et al., 2002; Isaksen and Lauer, 2002; Smith, 2010). Therefore, if employees feel free to have new ideas and do innovation, then it will be very critical in the trust of leader (Chandler et al., 2000).

Trust accelerates bilateral negotiation and the quality of cooperation to make personnel simply and more efficiency in the organization (Young and Wilkinson, 1989). Mayer et al. (1995) proposed trust affect the employees' degree of risk-taking and influence the willingness for sharing information. If there is no trust relationship in between, employees will worry the negative side of knowledge sharing, then reject the idea of devising. Therefore, there should be some influence between the leader and employees' trust relationship to share information and developing creativity.

Many scholars believe that the effect of creativity on leaders' supportive behavior to subordinate is important but lacking discussion. Innovation involves uncertainty and risk and in a higher risk situation, trust is more critical. The purpose of this research is finding what kind of behavior of the leader waking employees' feeling of supportive and causing them to take the risk for creativity. Also, it is going to prove the role of trust in the development of creativity. In enterprise, the development of employees' creativity has something to do with the support of leaders. In this study, we focus on finding what kind of leadership behavior will make employees to feel supportive then to exploit creativity, also knowing the role of trust from leader and employees' interaction. Therefore, the goal of this study is, first, to figure out whether or not the leader's supportive behavior will influence subordinates' creativity. Second, is there any affection of trust between leaders' supportive behavior and subordinates' creativity?

\section{MATERIALS AND METHODS}

Creativity: Creativity is simply the production of novel, appropriate ideas in any realm of human activity
(Amabile, 1997). The idea of novel is not just different from what has been done before but must be appreciate to the problem presented. Cates (1979) believed creativity is a flexible thinking ability and breaks the formal or old thinking model. However, the "connect" ability is also being concerned. Taylor (1959) said creativity is an ability connecting unrelated or $\mathrm{s}$ message to new products. Wiles defined creativity as an ability to connect different things and ideas to new relations. Also, creativity is a new idea or product, or connecting exist idea or product to a new form.

Some scholars believe creativity is a thinking process or the ability to solve problem in the thinking process using creativity to get creativity outcome. Creativity is a process of novel and sometimes having the new ideas (Albrecht and Hall, 1991). And creativity is novel or originally brain new (uncreative) or an important but useful product, idea or procedure (Oldham and Cumming, 1996). Isaksen and Lauer (2002) believed creativity is a re-hypothesis, revise or remodel the hypothesis to solve the problem. Therefore, the ability of solving unknown problem is called creativity.

Moreover, people get confused between creativity and innovation all the time, in fact, they are different. In general, creativity is the knowledge base of innovation that means the ability or a thinking process but innovation is an actual action that is product development or process improvement. Innovation is a process of making creativity thinking to a product or getting new ideas (Coade, 1999). Innovation and creativity are highly correlated.

In fact, biologist believed creativity comes from interaction between right and left part of brain. Psychologists concern deeply on its motivation, if individual has highly passion on one thing or really love to do one thing then the creativity will produce most and well performed. People will be most creative when they are primarily intrinsically motivated rather than extrinsically motivated (Amabile, 1997). Socialist believed creativity is not only a characteristic and they devoted on special social or environment will produce or influence one's creativity.

From above, we know the outcome of organizational creativity is not only decided on personal characteristic but organizational surrounding is directly or indirectly to effect it. For increasing employees' creativity most should be their supervisor in organization (Remond et al., 1993). Supervisory encouragement is a controllable and most directly factor (Amabile et al., 2004). 
Leadership and creativity: There are many ways to affect group, including model role, goal defining by supervisor. They also pass organization model and value, building group model and environment or organization climate. A leader doesn't necessary to have special creativity but to know how to manage other's creation and to blow other's potential (Tushman and O’Reilly, 1997).

Affecting employee's creativity by three ways: First, defining problem and showing an organization vision in the long-term over short-term business outcome more clearly, for example, growth and value rather than profit. Second, leaders are the key factor to effect organization climate and culture (Schein, 1992) by building supportive creativity climate and culture in the organization to boost employee's creativity. The leader can set up reward system for employees to involve in intrinsic and outer motivational environment (Jung et al., 2008). Amabile et al. (1996) developed conceptual model underlying assessment of perceptions of the work environment for creativity and found the supervisory encouragement; organizational encouragement and work group support positively affect creativity.

Supervisor support employees will increase their creativity, if leader control too much or with many limitations will jugulate creativity (Deci et al., 1989; Deci and Ryan, 1985; 1987). Oldham and Cummings (1996) believed the way of management to creativity is a main factor, supervisor should concern supporting and non-controlling to show his or her supportive of employees' feeling and needs. However, the importance of support to creativity is all known, but lacking a well construction on supportive behavior. In this study, we would like to know what kind of practice leadership and behavior will support subordinates to exploit creativity. Also, from the supportive behavior of supervisor, employee will take the risk of fail or not is testing the trust between them.

Trust: Since 1950, the concept of trust was noticed and became main topic. It includes psychology, sociology, organization behavior, economic and law area (Rousseau et al., 1998; Gambetta, 1988; Kramer and Tyler, 1995) and it was researched from different point of view and these days it is more concerned the playing role in an organization; management researchers concentrated on the actual effect of trust to the organization (Jones and Geroge, 1998). In the organization, one of the main factor to make a team cooperation more efficiency is the trust between team members; the success of organization change for leaders were relied in the degree of organization trust;
The organization climate of trust made members express their feelings and ideas, learning together and sharing information.

Mayer et al. (1995) believed that trust is trustor based on the expectation of others, no matter having the capability of controlling the trustee or not. He or she is willing to explore him or herself in a risky situation. From expectative perspective to view trust, it is a kind of situation that related with positive expectation from others' motivation and involved with unknown or noncontrolling risk (Lewicki and Bunker, 1996). La Porte and Metlay (1996) defined trust is trustor believes trustee will consider trustor's positive advantage even trustor will not control or interrupt trustee's negative behavior. From scholars' trust definition of above, we all know that trust is a personal subjective psychology status.

McCauley and Kuhnert pointed out trust in the organization has multi-dimensional direction. Costigan believed group is the foundation of working environment and trusting each other is quiet important for obtaining organization's goal. Some researchers believed interpersonal trust including cognitive and affected trust and dyadic trust means the interpersonal trust relationship of members to supervisor or coworker. This kind of trust will affect the willingness, motivation, confidence and assertiveness of an employee for taking risk. In social exchange viewpoint, it is focusing on the interaction relationship of interpersonal. Lewis and Weigert (1985) believed trust is a multi-dimension perspective and there are three types of it: (1) A cognitive psychological process and rational decision when trustor exchanger is worthiness to trust or not. (2) An emotional trust bases on the emotional mortgage and the truth of care from attending exchange activities. (3) The behavior trust is that trustor relies on trustee's behavior.

This study uses McAllister's pointed of view. Based on the Lewis and Weigert, he assorted personal trust in cognition-based and affect-based trust and defined as (1) cognition-based is trustor depends on cognition (the skill, interpersonal knowledge or professional task degree of trustee) to choose relying trustee or not. (2) Affect-based connotes a good intention, which means trustee banish self-seeking, to trustor representing non-return and altruism. And it shows partners are willing to care each other and believing their relationship and rely on this feeling. Therefore, we propose the following hypothesis:

H1-1: Leader support behavior and subordinate creativity are related.

H1-2: Leader support behavior and subordinate trust are related. 
H1-3: Subordinate to leader's trust and its creativity are highly related.

H2-1: Leader support behavior to subordinate creativity with effect.

H2-2: Leader support behavior to subordinate trust is highly related.

H2-3: Degree of trust of subordinate to leader to creativity with effect.

H2-4: The trust of subordinate to leader moderate leader behavior to subordinate's creativity.

Sample and procedure: Data for this study were collected from the employees highly interactive with their direct supervisor, group cooperation and nonroutine job character in the enterprise. All 400 full-time employees were surveyed, yielding 320 completed surveys ( $80 \%$ respond rate). Demographic data showed almost $72 \%$ of the employee held an above undergraduate degree. Respondents represented the six industrials: $32 \%$ electronic, $22 \%$ public advertising, $17 \%$ manufacture, $17 \%$ software design, $8 \%$ finance and $5 \%$ book trade $(62 \%$ were male and $38 \%$ were female). $78 \%$ of age was below 40 . The most organizational tenure was 1 to 3 years: $29 \%$, more than 10 years for $24 \%$. Almost $87 \%$ direct supervisors held an above undergraduate degree $(78 \%$ were male and $22 \%$ were female).

Measure: This study is using Amabile's research to analysis the supportive behavior. The questionnaire based on the cognition. Items used a 4-point format ranging from 1 (not at all) to 4 (to a great extent) for each scale measure. Testing trust, we use McAllister (1995) scale to measure affect-based and cognitionbased trust (Cronbach's $\alpha=0.91 ; 0.89$ ). On the part of creativity, we use Zhou and George (2001) developing the creativity scale to measure it (Cronbach's $\alpha=0.96$ ). Each questionnaire represents higher score with higher supportive behavior, trust or creativity. This study also use t-test and one-way ANOVA to test individual difference and the result shows creativity exploring and trust degree have nothing to do with individual difference.

\section{RESULTS AND DISCUSSION}

Using Pearson correlation to test the whole concept of the frame work, leaders' supportive behavior is positive related with creativity and trust and it has the same result with the literature review. Also, from the Table 1, absolute authority, autonomy and admiration leadership are all positive significant with creativity. Absolute authority, autonomy and admiration leadership are positive significant relation to both the affected and cognitive trust. But the supervision leadership has a negative significant relation with trust. For the trust and creativity, two constructs have positive significant correlations. Therefore, the higher degree of trust from leaders to employee will cause the higher performance on employees' creativity thinking and action.

The regression analysis is used to test the individual different leadership behavior to creativity. This regression Equation has 8 percent of explanation to creativity $\left(\mathrm{R}^{2}=0.08\right)$, absolute authority leadership behavior $(\beta=0.21, \quad \mathrm{p}<0.01)$, autonomy leadership behavior $(\beta=0.18, \mathrm{p}<0.05)$ are positive significant related and assign leadership behavior is negative significant related $(\beta=-0.20, \mathrm{p}<0.01)$. There is a 71 percent explanation of five leadership behavior constructs to trust $\left(\mathrm{R}^{2}=0.71\right)$. Absolute authority leadership behavior $(\beta=0.39, \mathrm{p}<0.01)$, autonomy leadership behavior $(\beta=0.29, \mathrm{p}<0.01)$ are positive significant related and supervision leadership behavior is negative significant related $(\beta=-0.12, \mathrm{p}<0.01)$. Also, trust to creativity is positive significant related $(\beta=$ $0.26, \mathrm{p}<0.01)$ and there is 6.5 percent explanation.

Table 1: The study of each variable related coefficient matrix

\begin{tabular}{|c|c|c|c|c|c|c|c|c|c|c|c|}
\hline & 1 & 2 & 3 & 4 & 5 & 6 & 7 & 8 & 9 & 10 & 11 \\
\hline \multicolumn{12}{|l|}{ Absolute Authority } \\
\hline Leadership B &.- & & & & & & & & & & \\
\hline Assign Leadership B. & $0.62 * *$ & - & & & & & & & & & \\
\hline Autonomy Leadership B. & $0.58 * *$ & $0.41 * *$ & - & & & & & & & & \\
\hline Admiration Leadership B. & $0.39 * *$ & $0.21 * *$ & $0.40 * *$ & - & & & & & & & \\
\hline Supervision Leadership B. & $-0.17 * *$ & -0.07 & $-0.31 * *$ & $-0.44 * *$ & - & & & & & & \\
\hline Affected Trust & $0.65 * *$ & $0.42 * *$ & $0.64 * *$ & $0.60 * *$ & $-0.46 * *$ & - & & & & & \\
\hline Cognitive Trust & $0.68 * *$ & $0.45 * *$ & $0.64 * *$ & $0.54 * *$ & $-0.39 * *$ & $0.77 * *$ & - & & & & \\
\hline Total Trust & $0.70 * *$ & $0.46 * *$ & $0.68 * *$ & $0.60 * *$ & $-0.44 * *$ & $0.92 * *$ & $0.96 * *$ & - & & & \\
\hline Creative Thinking & $0.17 * *$ & 0.01 & $0.21 * *$ & 0.10 & -0.07 & $0.18 * *$ & $0.23 * *$ & $0.22 * *$ & - & & \\
\hline Creative Action & $0.19 * *$ & 0.01 & $0.20 * *$ & $0.13^{*}$ & -0.07 & $0.22 * *$ & $0.22 * *$ & $0.23 * *$ & $0.58 * *$ & - & \\
\hline Total Creativity & $0.21 * *$ & 0.01 & $0.23 * *$ & $0.14 *$ & -0.08 & $0.23 * *$ & $0.25 * *$ & $0.26 * *$ & $0.80 * *$ & $0.95 * *$ & - \\
\hline Total Leadership B. & $0.95 * *$ & $0.74 * *$ & $0.69 * *$ & $0.48^{* *}$ & -0.09 & $0.67 * *$ & $0.70 * *$ & $0.73 * *$ & $0.16^{* *}$ & $0.18^{* *}$ & $0.19^{* *}$ \\
\hline
\end{tabular}


J. Social Sci., 7 (2): 257-264, 2011

Table 2: Trust moderating effect analysis

\begin{tabular}{|c|c|c|c|c|c|}
\hline \multirow[b]{2}{*}{ Dependent variable } & \multicolumn{5}{|l|}{ Creativity } \\
\hline & Equation $1(\beta)$ & Equation $2(\beta)$ & Equation $3(\beta)$ & Equation $4(\beta)$ & Equation $5(\beta)$ \\
\hline \multicolumn{6}{|l|}{ Independent variable } \\
\hline Absolute Authority Leadership B. & $0.21 * *$ & 0.16 & 0.14 & 0.15 & -0.12 \\
\hline Assign Leadership B. & $-0.20 * *$ & $-0.21 * *$ & -0.01 & $-0.21 * *$ & 0.42 \\
\hline Autonomy Leadership B. & $0.18 *$ & 0.14 & $-0.67 *$ & 0.13 & $-0.84 * *$ \\
\hline Admiration Leadership B. & 0.01 & -0.02 & -0.01 & -0.04 & -0.22 \\
\hline Supervision Leadership B. & 0.01 & 0.03 & -0.28 & 0.05 & -0.36 \\
\hline Cognitive Trust & & 0.14 & $-0.91 *$ & & \\
\hline Absolute A.L.B* C. T. & & & -0.05 & & \\
\hline Assign L.B.* C. T. & & & -0.32 & & \\
\hline Autonomy L.B.* C. T. & & & $1.66^{* *}$ & & \\
\hline Admiration L.B.* C. T. & & & 0.00 & & \\
\hline Supervision L.B* C. T. & & & 0.32 & & \\
\hline Affected Trust & & & & $0.19 *$ & $-1.29 * *$ \\
\hline Absolute A.L.B.* A.T. & & & & & 0.52 \\
\hline Assign L.B.* A.T. & & & & & $-1.03 *$ \\
\hline Autonomy L.B.* A.T. & & & & & $1.95^{* *}$ \\
\hline Admiration L.B.* A.T. & & & & & 0.35 \\
\hline Supervision L.B* A.T. & & & & & 0.39 \\
\hline R square & 0.08 & 0.09 & 0.13 & 0.09 & 0.17 \\
\hline Adjusted R square & 0.07 & 0.07 & 0.09 & 0.08 & 0.14 \\
\hline $\mathrm{F}$ value & $5.50 * *$ & $5.01 * *$ & $4.00 * *$ & $5.40 * *$ & $5.83 * *$ \\
\hline$P$ value & 0.00 & 0.00 & 0.00 & 0.00 & 0.00 \\
\hline
\end{tabular}

*: $\mathrm{p}<0.05 ;{ }^{* *}: \mathrm{p}<0.01$ (two-tailed); ${ }^{* *}: \mathrm{p}<0.00$

From Table 2 it can be seen, in order to know whether or not a significant moderating effect is between trust and the study model, we use five individual leadership behaviors to be the regression equation one. Overall trust and five leadership behavior constructs are equation two and the interaction of trust with each leadership behavior are equation three. The result shows each regression equation is significant and from equation three we may see a moderating effect for trust to autonomy leadership behavior and creativity ( $\beta$ $=2.196, \mathrm{p}<0.01)$. Also, the equation four find is trying to find out cognitive trust to the effect of this study model and it is the interaction between five constructs of leadership behavior and cognitive trust. The result shows cognitive trust to autonomy leadership behavior and employee's creativity has a moderating effect $(\beta=$ $1.656, \mathrm{p}<0.01)$. The last part tests the moderating effect of affected trust to this study model. The equation five is the interaction between affected trust and each leadership behavior. Result shows affected trust to autonomy leadership behavior and employee's creativity is a positive moderating effect $(\beta=1.946$, $\mathrm{p}<0.01$ ) and to assign leadership behavior is a negative moderating effect $(\beta=-1.028, p<0.05)$.

From the previous analysis, we found the supportive behavior of leaders, employees' creativity and employee to leaders' trust is significant related and trust is also partial moderating. By approving leaders' supportive behavior, we know it has significant correlation to subordinates' creativity and it also has a positive correlation to the trust degree of subordinates to leaders. And the trust degree to leaders and the exploring creativity of subordinates is also significant related. The supportive behavior to creativity and the trust degree are significant to both models and the trust degree of employees to leaders to employees' creativity is also positive related. Therefore, hypotheses are supported. In the moderating effect part, trust does affect autonomy leadership behavior to creativity and affected trust is also affecting the autonomy and the assign leadership behavior to creativity.

Scholars found there is no significant difference between personal characteristic and the degree of trust (Daley and Vasu, 1998). Our data shows personal characteristic, as gender, education, has no significant difference with the trust degree of employee to leader which means behavior is a more important factor. Personal characteristic also has no significant difference to creativity and it is also the same with our hypothesis which is that there are more important factors to affect personal creativity. Five dimensions are included in the research: absolute authority leader behavior, assign leader behavior, autonomy leader behavior, admiration leader behavior and supervision leader behavior. In fact, absolute authority leader behavior, autonomy leader behavior and admiration leader behavior have significant related with creativity.

Data shows the five dimensions of leader's supported behavior to affected, cognitive and overall trust has significant correlation $(\mathrm{R}$ square $=0.7$ ) and 
$71.1 \%$ of variance explained. Supervision leader behavior is negative related to trust and it is different with Amabile's study (a positive concept). The better explanation might be because the difference between eastern and western culture. Westerns concern more privacy than Eastern people and if leaders care more about employees' work in the non-office hours, the employees will be affected but eastern employees will be harried.

Chandler et al. (2000) believed that exploring the uncertainty and risk of creativity is more important to the trust of leaders. This study shows the trust degree of employees to leaders is positive significant related to creativity. When employees believe the supportive and commitment of leaders will cause employees to take the risk and perform creativity. Also, affected trust moderates assign and autonomy leader behavior to creativity. It shows leaders respect employees and let they get more autonomy, but there should be a trust building to explore creativity.

\section{CONCLUSION}

From this research, it indicates employees feel supportive behavior will help to cause creativity and trust is also an important factor. For creativity, first, leaders should build absolute power image, let employees believe that they have absolute power, including resource giving, solving problem or negotiating with others, to increase their security. Second, positive return and suggestion, if employees have new ideas, leaders should let employees feel that they are respected and avoid inappropriate criticizes and produce innovation together (Jaussi and Dionne, 2003; Corti et al., 2010). Third, highly individual concern, leaders are not only concern employees' job but also should care more about personal feeling in the daily life. Forth, trust employees and respect their work autonomy, leaders could express trust by using words, action or attitude and respect employees' voice. Fifth, admiring excellent performance, leaders should give positive appropriate encourage letting employees do creativity more.

For trust, first, lower supervision will build trust stronger. Then, clear objective to assign appropriate job, leaders should give employee specialty work, clear objective and decide deadline together, that is higher participate degree, to accelerate trust (Carifio, 2010). Also, they should avoid the same routine job in a long time.

There are also some limitations in this study. First, collecting sample use a convenience way and it may not control the target group. Second, the measure tool is developed and changed from scholars' qualitative research. There might be some misleading on the language or culture to influence validity and reliability.

For future research, the trust for higher-up to underling or between coworker to organization climate might be influenced in certain degree. If latter researchers could include it, then the study will be more complete. The questionnaire could be more mature developing for broadly use.

\section{REFERENCES}

Albrecht, T.L. and B.J. Hall, 1991. Facilitating talk about new ideas: The role of personal relationships in organizational innovation. Communi. Monographs, 58: 273-288. DOI: $10.1080 / 03637759109376230$

Amabile, T.M., 1988. A model of creativity and innovation in organizations. Res. Organ. Behav. http://drfd.hbs.edu/fit/public/facultyInfo.do?facInfo $=$ pub \& facId $=6409$

Amabile, T.M., 1997. Motivating creativity in organizations: On doing what you love and loving what you do. California Manage. Rev., 40: 39-58.

Amabile, T.M., E.A. Schatzel, G.B. Moneta and S.J. Kramer, 2004. Leader behaviors and the work environment for creativity: Perceived leader support. Leadership Q., 15: 5-32. DOI: 10.1016/j.leaqua.2003.12.003

Amabile, T.M., R. Conti, H. Coon, J. Lazenby and M. Herron, 1996. Assessing the work environment for creativity. Acad. Manage. J., 39: 1154-1184.

Andriopoulos, C. and A. Lowe, 2000. Enhancing organisational creativity: The process of perpetual challenging. Manage. Decision, 38: 734-742. DOI: 10.1108/00251740010379768

Carifio, J., 2010. Development and validation of a measure of relational leadership: Implications for leadership theory and policies. Curr. Res. Psychol., 1: 16-28. DOI: 10.3844/crpsp.2010.16.28

Cates, C., 1979. Beyond muddling: Creativity. Public Admin. Rev., 39: 527-532.

Chandler, G.N., C. Keller and D.W. Lyon, 2000. Unraveling the determinants and consequences of an inn ovation-supportive organizational culture. Entrepreneurship Theory Practice. http://www.questia.com/googleScholar.qst?docId= 5002378702

Coade, N., 1999. Be Creative: The Toolkit for Business Success. 1st Edn., International Thomson Business Press, India, ISBN-10: 1861520875, pp: 154. 
Corti, I.N., P.N. Marola and M.B. Castro, 2010. Social inclusion and local development through European Voluntourism: A case study of the project realized in a neighborhood of morocco. Am. J. Econ. Bus. Admin., 2: 221-231. DOI: 10.3844/ajebasp.2010.221.231

Cummings, A. and G.R. Oldham, 1997. Enhancing creativity: Managing work contexts for high potential employee. California Manage. Rev., 40: 22-38.

Daley, D.M. and N.L. Vasu, 1998. Fostering organizational trust in North Carolina: The pivotal role of administrators and political leaders. Admin. Soc., 30: 62-84. 10.1177/009539979803000105

Deci, E.L. and R.M. Ryan, 1985. Intrinsic Motivation and Self-Determination. 1st Edn., Springer, USA., ISBN-10: 0306420228, pp: 371.

Deci, E.L. and R.M. Ryan, 1987. The support of autonomy and the control of behavior. $\mathrm{J}$. Personality Soc. Psychol., 53: 1024-1037. PMID: 3320334

Deci, E.L., J.P. Connell and R.M. Ryan, 1989. Selfdetermination in a work organization. J. Applied Psychol., 74: 580-590. DOI: 10.1037/00219010.74.4.580

Dess, G.G. and J.C. Pickens, 2000. Changing roles: Leadership in the 21 st century. Organ. Dynamics, 28: 18-34. DOI: 10.1016/S0090-2616(00)88447-8

Gambetta, D., 1988. Trust: Making and Breaking Cooperative Relations. 1st Edn., B. Blackwell, UK., ISBN-10: 0631175873, pp: 246.

Hage, J. and R. Dewar, 1973. Elite values versus organizational structure in predicting innovation. Admin. Sci. Q., 18: 279-290.

Isaksen, S.G. and K.J. Lauer, 2002. The climate for creativity and change in Teams. Creativity Innov. Manage., 11: 74-86. DOI: 10.1111/14678691.00238

Jaussi, K.S. and S.D. Dionne, 2003. Leading for creativity: the role of unconventional leader behavior. Leadership Q., 14: 475-498. DOI: 10.1016/S1048-9843(03)00048-1

Jones, G.R. and J.M. George, 1998. The experience and evolution of trust: Implications for cooperation and teamwork. Acad. Manage. Rev., 23: 531-546.

Jung, D., A. Wu and C.w. Chow, 2008. Towards understanding the direct and indirect effects of CEO's transformational leadership on firm innovation. Leadership Q., 19: 582-594. DOI: 10.1016/j.leaqua.2008.07.007

Kramer, R.M. and T.R. Tyler, 1995. Whither trust? In: Trust in Organization: Frontiers of Theory and Research, 1st Edn., Sage Publications, India, ISBN-10: 0803957408, pp: 429.
La Porte, T.R. and D.S. Metlay, 1996. Harzards and institutional trustworthiness facing a deficit of trust. Public Admin. Rev., 56: 341-347.

Lewicki, R.J. and B.B. Bunker, 1996. Developing and Maintaining Trust in Work Relationships. 1st Edn., Max M. Fisher College of Business, Ohio State University, USA., pp: 25.

Lewis, J.D. and A. Weigert, 1985. Trust as a social reality. Soc. Force, 63: 967-985. DOI: $10.2307 / 2578601$

Mayer, R.C., J.H. Davis and F.D. Schoorman, 1995. An integrative model of organizational trust. Acad. Manage. Rev., 20: 709-734. DOI: 10.2307/258792

McAllister, D.J., 1995. Affect- and cognition-based trust as foundations for interpersonal cooperation in organizations. Acad. Manage. J., 38: 24-59. DOI: $10.2307 / 256727$

Oldham, G.R. and A. Cummings, 1996. Employee creativity: Personal and contextual factors at work. Acad. Manage. J., 39: 607-634. DOI: $10.2307 / 256657$

Ragazzoni, P., P. Baiardi, A.M. Zotti, N. Anderson and M. West, 2002. Italian validation of the team climate inventory: A measure of team climate for innovation. J. Managerial Psychol., 17: 325-336. DOI: $10.1108 / 02683940210428128$

Remond, M.R., M.D. Mumford and R. Teach, 1993. Putting creativity to work: Effects of leader behavior on subordinate creativity. Organ. Behav. Hum. Decision Process, 55: 120-151. DOI: 10.1006/obhd.1993.1027

Rousseau, D.M., S.B. Sitkin, R.S. Burt and C. Camerer, 1998. Not so different after all: A cross-discipline view of trust. Acad. Manage. Rev., 23: 393-404. DOI: 10.1016/S0099-1767(98)90076-9

Rubenson, D.L. and M.A. Runco, 1992. The psychoeconomic approach to creativity. New Ideas Psychol., 10: 131-147. DOI: 10.1016/0732118X(92)90021-Q

Schein, E.H., 1992. Organizational Culture and Leadership: A Dynamic View. 1st Edn., Natl Book Network, USA., ISBN-10: 0783765053, pp: 358.

Smith, G., 2010. A study of clinical behavior in intensive care unit. Int. J. Res. Nurs., 1: 21-24. DOI: $10.3844 /$ ijrnsp.2010.21.24

Smith, G.P., 2002. The New Leader: Bringing Creativity and Innovation to the Workplace. 2nd EdnSt. Lucie Press, India, ISBN-10: 1574440349, pp: 264.

Tushman, M. and C.A. O'Reilly, 1997. Winning through Innovation: A Practical Guide to Leading Organizational Change and Renewal. 1st Edn., Harvard Business School Press, Cambridge, MA., ISBN-10: 0875845797, pp: 259. 
Woodman, R.W., J.E. Sawyer and R.W. Griffin, 1993. Toward a theory of organizational creativity. Acad. Manage. Rev., 18: 293-321.
Young, L.C. and I.F. Wilkinson, 1989. The role of trust and co-operation in marketing channels: A preliminary study. Eur. J. Market., 23: 109-122. DOI: 10.1108/EUM0000000000550 